\title{
Complex Formation of Polyamides Containing Dibenzo-18- Crown-6 Moieties with Alkali Metal Ions
}

\author{
Jung-Il JIN, Myong-Soo LEE,* and Si-Joong KIM \\ Department of Chemistry, College of Sciences, \\ Korea University, 1-Anam Dong, Seoul 132, Korea
}

(Received March 6, 1984)

\begin{abstract}
New polyamides containing dibenzo-18-crown-6 structural units along the main chain were synthesized from cis- or trans-4,4'-diaminodibenzo-18-crown-6 and a 4,4'-dicarboxy$\alpha, \omega$-diphenoxyalkane. In addition to their general properties, the complexing capabilities of polymers with alkali metal ions were studied by examining their solution viscosities in the presence of the $p$-toluenesulfonates of $\mathrm{Rb}^{+}, \mathrm{K}^{+}, \mathrm{Na}^{+}$, and $\mathrm{Li}^{+}$and potassium salts of $\mathrm{CH}_{3} \mathrm{C}_{6} \mathrm{H}_{4} \mathrm{SO}_{3}{ }^{-}$, $\mathrm{SCN}^{-}, \mathrm{I}^{-}$, and $\mathrm{Br}^{-}$. The viscosity of the polymer solutions in the presence of $\mathrm{K}^{+}$or $\mathrm{Rb}^{+}$salts resembled that of typical polyelectrolytes, with reduced viscosities strongly enhanced at low concentrations. This was explained in terms of complexation between the metal ions and the crown ether moieties in the polymer chain.
\end{abstract}

KEY WORDS Polyamides / Crown Ether / 4,4'-Diaminodibenzo-18-

Crown-6. / 4,4'-Dicarboxy- $\alpha, \omega$-diphenoxyalkane / Solution Viscosity /

Complex / Polyelectrolyte /

Since Pedersen ${ }^{1}$ reported the synthesis and properties of macrocyclic polyethers or crown ethers, polymers containing various crown ether moieties along the main backbone or in side chains are attracting a great deal of interest among polymer scientists due to their cation-binding properties. $^{2-7}$ The polymers, depending on the structure of the crown ether unit, reveal ion selectivities in their formation of cation complexes, in a manner similar to their corresponding monomeric counterparts. Shchori and Jagur-Grodzinski ${ }^{6}$ prepared polyamides from $\mathrm{cis}$-4,4'-diaminodibenzo-18crown-6 and iso- or terephthaloyl chloride and studied the permeability of alkali metal cations through membranes made of these polymers. According to their results, the polymer membranes adsorbed $\mathrm{Na}^{+}$much more strongly than $\mathrm{Li}^{+}$. This enabled them to selectively separate $\mathrm{Na}^{+}$from a solution of $\mathrm{Na}^{+}$and $\mathrm{Li}^{+}$.
The salt rejection properties were excellent. In addition, poly(vinylpyrrolidone) had a stabilizing effect on the permeability characteristics of the membrane.

In the present study, we have prepared several new polyamides containing dibenzo18-crown-6 moieties and alkylene units in the main chain. The viscosity of their solutions in the presence of various alkali metal cations and counter anions was investigated. The polyamides were prepared by reacting

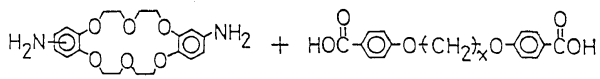

$$
\begin{aligned}
& \text { cis or trans DAC DCA, } x=2 \text { or } 10
\end{aligned}
$$

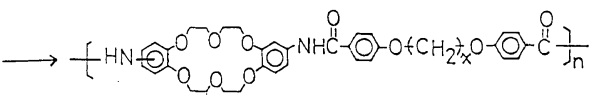

cis- or trans-4,4'-diaminodibenzo-18-crown-6$(\mathrm{DAC})^{8,9}$ and a $4,4^{\prime}$-dicarboxy- $\alpha, \omega$-diphen-

\footnotetext{
* Present address: Korea Research Institute of Chemical Technology, Dae-Jon City, Korea.
} 
oxyalkane (DCA $)^{10}$ using the polycondensation method reported by Ogata et al. ${ }^{11} \mathrm{We}$ designate the polymers as trans-2, trans-10, cis2 or $c i s-10$, depending on the structure of the DAC unit and the length, $x$, of the alkylene unit.

\section{EXPERIMENTAL}

\section{Polymer Preparation}

cis- and trans-DAC and the DCA's were prepared following the literature method. ${ }^{8,9} \mathrm{~A}$ representative method used for the synthesis of polymers was as follows: trans-DAC $(0.01$ mol) and 4,4'-dicarboxy-1,10-diphenoxydecane $(0.01 \mathrm{~mol})$ were dissolved in $20 \mathrm{ml}$ of pyridine containing $0.024 \mathrm{~mol}$ of triphenylphosphine and then $0.03 \mathrm{~mol}$ of hexachloroethane was added to the solution with stirring. The mixture was stirred for $30 \mathrm{~min}$ at room temperature. The viscous polymerization mixture was poured into a large excess of acetone. The precipitate was thoroughly washed with acetone, water and finally with methanol, before drying.

\section{Characterization of Polymers}

The structures of the polymers were confirmed by their IR spectra, obtained on a Perkin-Elmer IR Spectrometer 710B. The melting points of the polymers shown in Table I were obtained by differential scanning calorimetry (du Pont 910) under a nitrogen atmosphere. The heating rate was $10 \mathrm{~K} \mathrm{~min}^{-1}$. The solution viscosities of the polymers were measured with an Ubbelohde viscometer at $30^{\circ} \mathrm{C}$. When required, the viscosities were measured in the presence of a predetermined amount of an alkali salt.

\section{RESULTS AND DISCUSSION}

\section{General Properties of the Polyamides}

All of the polymers showed distinct melting transitions (Table I) on DSC thermograms, indicating their semicrystalline nature. The polymers prepared from the trans-diamino compound possessed significantly higher melting points than their cis counterparts, as one can see from Table I. The trans polymers, due to their favorable geometric structure, seemed to form more efficiently packed crystalline regions, resulting in higher melting temperatures. The melting points of the polymer with the shorter alkylene unit, ethylene, in their chain were consistently higher than those with the longer decamethylene unit.

The molecular weights of the polymers appeared to be rather low, as reflected by their relatively low solution viscosities (see Table I). We did not try to optimize the synthetic conditions to improve the molecular weights of the polymers, although we expected that it could have been done. The polyamides were soluble in such solvents as $m$-cresol, $N, N$ dimethylacetamide containing $5 \mathrm{wt} \% \mathrm{LiCl}$, and hexamethylphosphoramide. Chlorinated hydrocarbons did not dissolve the polymers.

Solution Viscosity Behavior of the Polymers in the Presence of Alkali Metal Salts

It is well-known that polymers carrying crown ether moieties in side chains ${ }^{2,12}$ or in the main chain ${ }^{6}$ form complexes with alkali metal and other cations. In the presence of complexable cations, they exhibited solution viscosity behavior typical of polyelectrolytes. ${ }^{13} \mathrm{We}$ have measured solution viscosities of the polymers

Table I. Synthesis and properties of polyamides

\begin{tabular}{|c|c|c|c|}
\hline \multirow{2}{*}{ Designation } & Yield & \multirow{2}{*}{$\eta_{\text {inh. }}{ }^{\mathrm{a}}$} & \multirow{2}{*}{$\frac{\mathrm{mp}^{\mathrm{b}}}{{ }^{\circ} \mathrm{C}}$} \\
\hline & $w t \%$ & & \\
\hline trans -2 & 94.2 & 0.138 & 336.5 \\
\hline trans -10 & 92.0 & 0.133 & 271.5 \\
\hline$c i s-2$ & 95.6 & 0.136 & 287.5 \\
\hline cis-10 & 89.0 & 0.134 & 224.5 \\
\hline
\end{tabular}

a Inherent viscosity numbers were measured at the concentration of $0.2 \mathrm{~g} \mathrm{dl}^{-1}$ in $N, N$-dimethylacetamide containing $5 \mathrm{wt} \% \mathrm{LiCl}$ at $30^{\circ} \mathrm{C}$.

b The peak maximum positions were taken as those of melting transition points. 


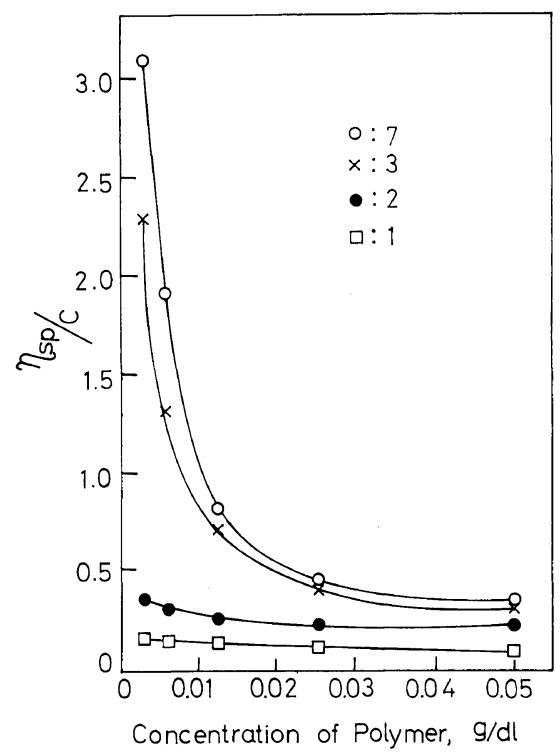

Figure 1. Dependence of reduced viscosity on concentration of trans-2-polymer in $\mathrm{N}, \mathrm{N}$-dimethylacetamide in the presence of potassium $p$-toluenesulfonate salt at the concentration ratios of $\left[\mathrm{K}^{+}\right] /[$crown $]=$ $1,2,3$, and 7 .

in the presence of varying amounts of different alkali metal salts (Figures 1 to 4 ). The solvent used was $N, N$-dimethylacetamide. The solution viscosity of the polymer in each case was measured on successive dilutions of the original solution. Figure 1 shows how the reduced viscosity of trans- 2 polymer changed as the polymer concentration decreased. The molar ratio of the salt, potassium $p$-toluenesulfonate, to the crown ether moieties in the polymer chain was varied from 1 to 7 . This figure tells us two different phenomena: (1) the higher the salt concentration, the higher the solution viscosity of the polymer, and (2) the higher the molar ratios of salt to crown ether units, the steeper increase in solution viscosity upon dilution. But the increase became much less pronounced at salt to crown ether unit molar ratios greater than three.

Nevertheless, when the ionic strength was kept constant, no increase in solution viscosity at low concentrations was observed. Such observations can be explained by assuming that

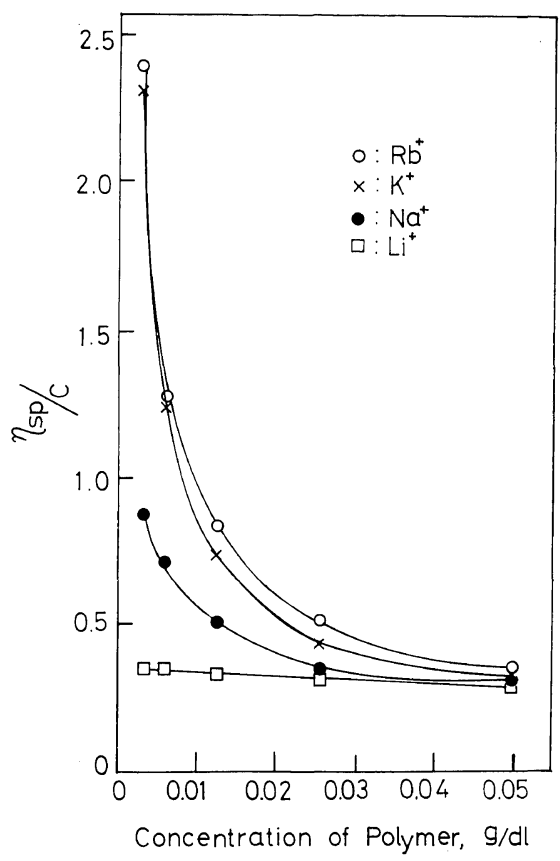

Figure 2. Dependence of reduced viscosity of trans-2polymer in $N, N$-dimethylacetamide in the presence of various alkali metal $p$-toluenesulfonate salts at the constant ratio of $\left[\mathrm{M}^{+}\right] /[$crown $]=3$.

the formation of the crown ether moiety- $\mathrm{K}^{+}$ complexes is favored at higher molar ratios of $\mathrm{K}^{+}$: crown ether unit. Also, at higher polymer-salt concentrations, ion pairing should occur between the crown ether- $\mathrm{K}^{+}$ complexes and the counter ion, the $p$ toluenesulfonate anion. On dilution, complex ion pairs would dissociate to a higher degree interchain electrorepulsion between the similarly charged, i.e., positively charged, commilarly charged, i.e., positively charged, complexed chain segments, resulting in the expansion of polymer chains which, in turn, would give rise to an increase in solution viscosity as observed in the present system. Such an increased degree of dissociation cannot be expected to occur when ionic strength is kept constant, because of the large excess of salt present. This is the reason why the solution viscosity does not increase on dilution.

The effect of the nature of the alkali metal 


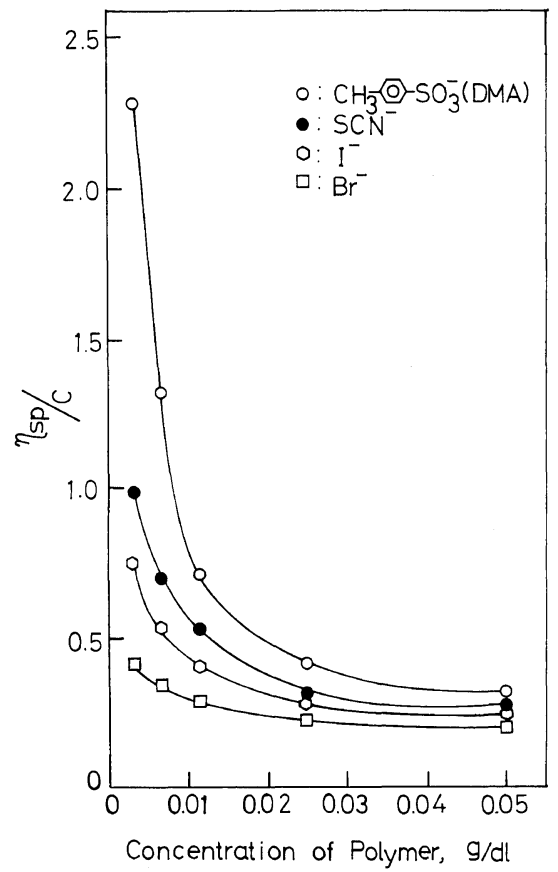

Figure 3. Dependence of reduced viscosity of trans-2polymer in $N, N$-dimethylacetamide in the presence of various potassium anion at the constant ratio of $\left[\mathrm{K}^{+}\right] /$ [crown] $=3$.

ion on solution viscosity is depicted in Figure 2. The solution viscosity of trans-2 polymer was measured in the presence of $p$ toluenesulfonates of various alkali metals. The molar ratio of metal ion to crown ether moiety was kept constant at three. The enhancement in solution viscosity of the polymer parallels the ability of the alkali metal ions to form complexes with the crown ether moiety ${ }^{1}$ : $\mathrm{Rb}^{+} \geq \mathrm{K}^{+}>\mathrm{Na}^{+}>\mathrm{Li}^{+}$. This observation again confirm that complex formation between the crown ether moieties in the main chain and the metal ions causes conformational changes in the polymer chains upon dilution. In contrast to other ions, $\mathrm{Rb}^{+}$, due to its large size, is probably forming sandwich-type complexes, ${ }^{14}$ whose formation should be particularly favored by the coil conformation of the polymer chains and by the proximity of their crown ether moieties.

The solution viscosity of the polymers is

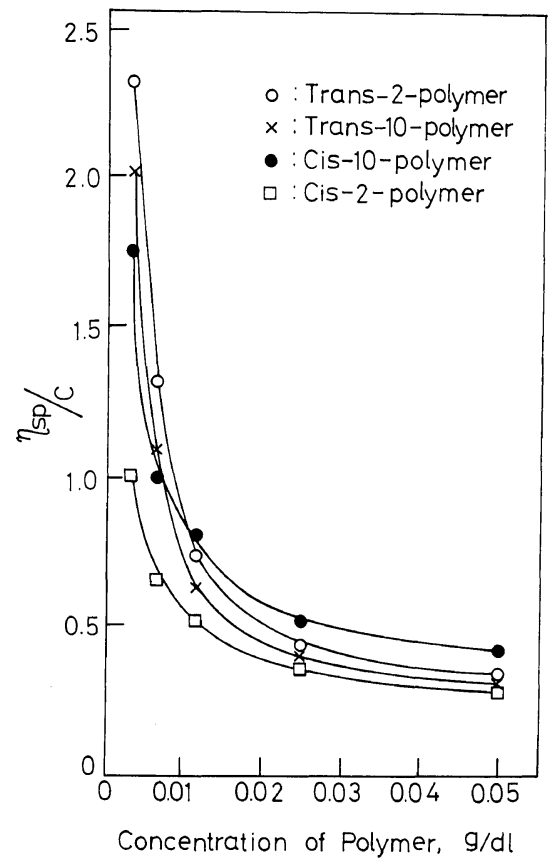

Figure 4. Dependence of reduced viscosity on the structure of polymers in $N, N$-dimethylacetamide in the presence of potassium $p$-toluenesulfonate salt at the constant molar ratio of $\left[\mathrm{K}^{+}\right] /[$crown $]=3$.

influenced by the tightness of the ion pairs of crown ether $-\mathrm{K}^{+}$complex and counter anion and thus should be dependent on the structure of the anion. We measured solution viscosities of the trans-2 polymer in the presence of potassium salts of various anions: $\mathrm{CH}_{3} \mathrm{C}_{6} \mathrm{H}_{4} \mathrm{SO}_{3}{ }^{-}, \mathrm{SCN}^{-}, \mathrm{I}^{-}$and $\mathrm{Br}^{-}$. The results are presented in Figure 3. The degree of increase in solution viscosity upon dilution, in the presence of the corresponding potassium salt, was $\mathrm{CH}_{3} \mathrm{C}_{6} \mathrm{H}_{4} \mathrm{SO}_{3}{ }^{-}>\mathrm{SCN}^{-}>\mathrm{I}^{-}>\mathrm{Br}^{-}$. This order is the inverse of the expected anion capability to form tighter ion pairs. ${ }^{15}$ In other words, bromide forms the tightest ion pair with the crown ether- $\mathrm{K}^{+}$complex, while $p$ toluenesulfonate forms the loosest. This loose ion pair would tend to dissociate more readily upon dilution and would result in stronger electrorepulsion between the positively charged crown ether- $\mathrm{K}^{+}$complex segments close to each other. Therefore, the anion 
which forms the loosest ion pair will show the steepest increase in solution viscosity of the polymer on dilution, as observed in the present investigation.

Finally, we tried to see whether a minor change in polymer structure can be reflected in solution viscosity behavior. The results are shown graphically in Figure 4. In general, the solutions of trans polymers showed a steeper increase in viscosity than those of their cis counterparts as the solutions were diluted. This probably is due to the inherently bent structure of cis polymer chains caused by the cis position of the two amide groups on the crown ether units in the polymer chain. Such a bent structure would result in a relatively less expanded shape of the polymer molecules on dilution compared with trans polymers. Therefore, cis polymers would exhibit a more gentle increase in solution viscosity upon dilution of the solution, as demonstrated in Figure 4.

One of our earlier communications ${ }^{16}$ described a preliminary solution light scattering study of trans-10 polyamide in the presence of potassium $p$-toluenesulfonate. It showed that in concentrated solutions the polymer retains a Gaussian coil form, but when diluted it tends to undergo conformational changes to elongated shapes. This result is consistent with those described in this report.

Acknowledgement. We gratefully acknowledge the Ministry of Education of the Re- public of Korea for the financial support of this study through the Basic Science Research Program. J.-I. Jin wishes to express his sincere thanks to Dr. Robert Ausubel for many useful suggestions in the preparation of this article.

\section{REFERENCES}

1. C. J. Pedersen, J. Am. Chem. Soc., 89, 7017 (1967).

2. S. Kopolow, T. E. Hogen Esch, and J. Smid, Macromolecules, 6, 133 (1973).

3. K. Kimura, T. Maeda, and T. Shono, Makromol. Chem., 182, 1579 (1981).

4. J. Anzai, A. Ueno, Y. Suzuki, and T. Osa, Makromol. Chem., Rapid Commun., 3, 55 (1982).

5. M. Shirai, T. Orikata, and M. Tanaka, Makromol. Chem., Rapid Commun., 4, 65 (1983).

6. E. Shchori and J. Jagur-Grodzinski, J. Appl. Polym. Sci., 20, 773 (1976).

7. E. Shchori and J. Jagur-Grodzinski, J. Appl. Polym. Sci., 20, 1665 (1976).

8. E. Shchori, J. Jagur-Grodzinski, and M. Shporer, $J$. Am. Chem. Soc., 95, 3842 (1973).

9. W. M. Feigenbaum and R. H. Michel, J. Polym. Sci., $A-1,9,817$ (1971).

10. A. C. Griffin and S. J. Havens, J. Polym. Sci., Polym. Phys. Ed., 19, 951 (1981).

11. G.-C. Wu, H. Tanaka, K. Sanui, and N. Ogata, $J$. Polym. Sci., Polym. Lett. Ed., 19, 343 (1981).

12. S. Kopolow, Z. Machacek, U. Takaki, and J. Smid, J. Macromol. Sci. Chem., 7, 1015 (1973).

13. H. Morawetz, "Macromolecules in Solution, 2nd Ed.," John Wiley \& Sons, Inc., New York, N. Y., 1975, Chapter VII.

14. D. Bright and M. R. Truter, Nature (London), 225, 176 (1970); J. Chem. Soc., B, 1544 (1970).

15. C. H. Chang, Ph. D. Dissertation, Korea University, Seoul, Korea, July, 1981.

16. D. C. Kim, T. K. Lim, and J.-I. Jin, Sci. Tech. (Korea University), 24, 157 (1983). 